\title{
Blood banks call for calm over virus scare
}

\section{Jonathan Knight, San Francisco}

As birds and mosquitoes continue to spread West Nile virus (WNV) across the United States, fears have erupted that organ transplants and blood transfusions are also transmitting the virus. But even though WNV can cause a lethal brain inflammation in infected people, screening procedures for blood donors are unlikely to be put in place.

Long endemic to Africa, Asia and southern Europe, WNV arrived in New York in 1999. By summer 2001, it had moved west of the Mississippi. It may now have completed its coast-to-coast march, with a Los Angeles woman returning a positive preliminary test.

WNV is transmitted between birds by mosquitoes, but people and horses can also be infected. The current season is the worst so far - almost 1,000 people have been infected with the virus, and 43 have died.

Questions about the blood supply first

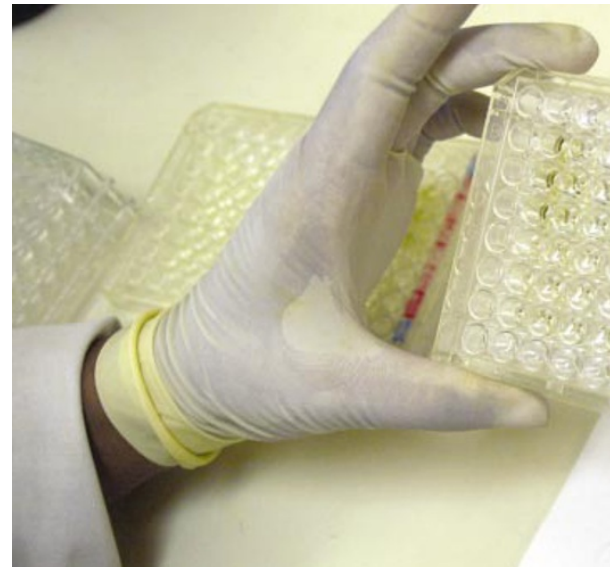

Keeping track: a technician in Louisiana tests blood samples for signs of the deadly West Nile virus.

emerged on 31 August, when officials from the Centers for Disease Control and Prevention (CDC) in Atlanta, Georgia, said they were investigating the case of a Georgia woman given blood from more than 60 donors following a traffic accident. After she died on 1 August, her organs were transplanted to four recipients, all of whom became infected with WNV. One died of encephalitis.

On 5 September, Mississippi health officials said that they were looking into the case of a woman who had received 18 units of blood during surgery several weeks before developing West Nile encephalitis. Investigators are still determining whether any of the blood donors in either case was infected with WNV.

Blood donated in the United States is tested for HIV, the leukaemia viruses HTLV 1 and 2, and hepatitis B and C. In addition, white cells are filtered out to remove herpes viruses. Each test costs up to several dollars per donation,

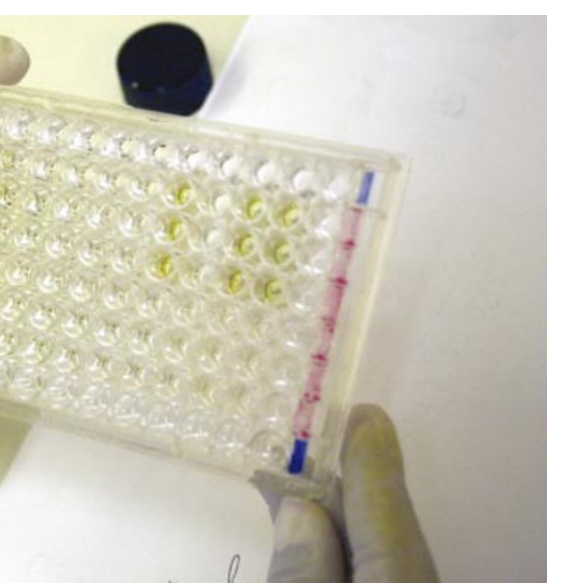

and new tests are subject to a development and approval process that can take years.

To warrant such a step for WNV, it would have to pose a greater risk than problems already faced by blood banks. From preliminary studies, the CDC estimates that about 1 in 150 infected people develop encephalitis. This suggests that some 150,000 Americans, or 1 in 2,000 people, have been infected this summer, most without knowing it. If a person donated at the peak of infection, the virus might well be transmitted, says Michael Turell of the US Army Medical Research Institute of Infectious Diseases in Fort Detrick, Maryland. But because WNV circulates in the blood for only a few days or weeks, the chances of donors passing it on remain low.

Given these statistics, suggests Michael Busch, vice-president of research at Blood Centers of the Pacific, a San Francisco blood bank, testing for WNV is a lower priority than, for example, detecting low-level bacterial contamination. Bacteria can multiply while blood is stored, and the resulting infections cause about one death for every million units of blood given in the United States.

But the risks may change as WNV spreads. Health officials are on the lookout for the virus, which usually turns up in birds before the first human cases emerge (see Nature 417, 477; 2002). For this reason, California is using some 200 flocks of 'sentinel' chickens to detect the virus; these have so far remained negative.

But on 6 September, Los Angeles health officials reported a positive test for WNV in a woman who had not left the state in some time. Because the test used can crossreact with other viruses, they were awaiting confirmatory tests by the CDCas Nature went to press. nww.cdc.gov/ncidod/dvbid/westnile

\section{Universities urged to get with IT for biology}

Kendall Powell, Washington

Biology teachers in universities need to infuse their curricula with more computer science, mathematics and physical sciences, according to leading US scientists.

More cross-disciplinary teaching is needed to keep students up to date with the growing role of computers in biology and the impact of the molecular-genetics revolution, the academics say.

"The way we carry out science is profoundly different from 20 or 30 years ago," says Lubert Stryer, a neurobiologist at Stanford University in California. "But education even at the very best schools has changed very little." Stryer chaired a National Research Council panel that looked into undergraduate biology education and released its findings in a report on 10 September.

Mounting concerns that undergraduate education in the United States is failing to produce enough young biologists with the skills and motivation to go into research prompted the National Institutes of Health and the Howard Hughes Medical Institute to commission the study.

Although current biology research relies more heavily on computer modelling, information technology and complex instrumentation, undergraduate courses and textbooks have stuck to the facts of life science and not much else, Stryer's panel claims. It also advocates more teaching on the history of science and the process of discovery.

Diane Shakes, who teaches cell biology at the College of William \& Mary in Williamsburg, Virginia, describes the panel's findings as a "noble goal" but sees significant hurdles for smaller teaching universities. She says that hiring interdisciplinary faculty to teach integrated courses would pose problems for small campus departments.

To implement the changes, the study advises using movies, computer presentations, and adding ready-made physics or chemistry modules to existing courses. Team-teaching across academic departments is also recommended.

Stryer hopes that government agencies and private companies will come forward with funds to support teaching workshops and develop educational materials to support the goals of the report. 